\title{
Further delineation of the phenotype of chromosome $14 q 13$ deletions: (positional) involvement of FOXG1 appears the main determinant of phenotype severity, with no evidence for a holoprosencephaly locus
}

Gijs W E Santen, ${ }^{1}$ Yu Sun, ${ }^{1}$ Antoinet C J Gijsbers, ${ }^{1}$ Aurore Carré, ${ }^{2}$ Maureen Holvoet, ${ }^{3}$ Arie van Haeringen, ${ }^{1,4}$ Saskia A J Lesnik Oberstein, ${ }^{1}$ Akemi Tomoda, ${ }^{5}$ Hiroyo Mabe, ${ }^{6}$ Michel Polak, ${ }^{7}$ Koenraad Devriendt, ${ }^{3}$ Claudia A L Ruivenkamp, ${ }^{1}$ Emilia K Bijlsma ${ }^{1}$

${ }^{1}$ Center for Human and Clinical Genetics, Leiden University Medical Center (LUMC), Leiden, The Netherlands

${ }^{2}$ INSERM U 845, UMR 8200 CNRS, Institut Gustave Roussy, Villejuif, France

${ }^{3}$ Center for Human Genetics, University Hospital Leuven and K.U.Leuven, Leuven, Belgium ${ }^{4}$ Department of Clinical Genetics, Juliana Children's Hospital/HAGA Teaching Hospital, The Hague, The Netherlands

${ }^{5}$ Research Center for Child Mental Development, Graduate School of Medical Sciences, University of Fukui, Fukui, Japan ${ }^{6}$ Department of Child Development, Faculty of Life Sciences, Kumamoto University, Kumamoto, Japan

${ }^{7}$ Université Paris Descartes, Sorbonne Paris Cité, INSERM U845, Pediatric endocrinology, AP-HP, Hôpital Necker Enfants Malades, Paris, France

\section{Correspondence to}

Dr Gijs W E Santen, Center for Human and Clinical Genetics, Leiden University Medical Center (LUMC), Albinusdreef 2, Postbus 9600, Leiden 2300 RC The Netherlands; santen@lumc.nl

Received 9 February 2012 Accepted 2 April 2012

\section{ABSTRACT}

Background Deletions including chromosome 14 band q13 have been linked to variable phenotypes. With current molecular methods the authors aim to elucidate a genotype-phenotype correlation by accurately determining the size and location of the deletions and the associated phenotype.

Methods Here the authors report the molecular karyotyping and phenotypic description of seven patients with overlapping deletions including chromosome 14q13.

Results The authors show that deletions including $14 q 13$ result in a recognisable phenotype mainly due to haploinsufficiency of two genes (NKX2-1, PAX9). FOXG1 (on chromosome band 14q12) involvement seems to be the main determinant of phenotype severity. The patients in this study without FOXG1 involvement and deletions of up to $10 \mathrm{Mb}$ have a relatively mild phenotype. The authors cannot explain why some patients in literature with overlapping but smaller deletions appear to have a more severe phenotype. A previously presumed association with holoprosencephaly could not be confirmed as none of the patients in this series had holoprosencephaly.

Conclusions FOXG1 appears the main determinant of the severity of phenotypes resulting from deletions including 14q13. The collected data show no evidence for a locus for holoprosencephaly in the $14 q 13$ region, but a locus for agenesis of the corpus callosum cannot be excluded.

\section{INTRODUCTION}

With the advent of array-based molecular karyotyping more precise delineation of copy number variants has become the standard. This technical advance has stimulated a search for genotypephenotype correlations in patients with deletions in the same chromosomal region with variable phenotypes. Illustrative examples of this type of research are studies on deletions in chromosome 19p13.12 $2^{1}$ and 18q. ${ }^{2}$ Genotype-phenotype relations are important for several reasons: (1) when a deletion is detected in a neonate, young child or even prenatally, the parents can be informed about the expected phenotype of their child, and treatment/surveillance can be adapted to the expected phenotype and (2) candidate genes for monogenic disorders may be found.

Deletions including 14q13 have been described repeatedly in literature..$^{3-11}$ In several of these publications, a $14 q 13$ deletion has been linked to holoprosencephaly (HPE) that led to the definition of a holoprosencephaly locus (HPE8). ${ }^{3}{ }^{8-10}$ Deletions of the NKX2-1 (TITF1) gene dominate the phenotype of the remaining publications. ${ }^{5-7} 1112$ However, clinical data are often sparse and most of these publications rely on conventional karyotyping or focus on only one or two genes (NKX2-1, $P A X 9)$ in the deletion. Recently, two papers have appeared describing additional patients with a deletion including $14 \mathrm{q} 13$ and a severe phenotype, ${ }^{1314}$ although the patients in the latter paper ${ }^{14}$ have much larger deletions including chromosome band $14 q 12$ and FOXG1.

Here, we present the molecular karyotyping and the phenotypic description of seven patients with overlapping $14 \mathrm{q} 13$ deletions, and compare the results with patients reported in the literature.

\section{MATERIALS AND METHODS Molecular karyotyping}

For patients 1, 2, 3, 6 and 7 DNA was extracted from whole blood by a Gentra Puregene DNA purification Kit (Gentra Systems, Minneapolis, USA), following the manufacturer's instructions. The Affymetrix GeneChip Human Mapping 262K NspI array (Affymetrix, Santa Clara, California, USA) was performed following the manufacturer's instructions and data were analysed as described previously. $^{15}$

For patients 4 and 5, array-CGH was performed by means of the '180k Cytosure ISCA v2 array', 'Oxford Gene Technology', according to standard procedures

\section{CLINICAL REPORTS}

In total, seven patients were included of whom three (patients 4, 6 and 7) were published previously. ${ }^{5} 1112$ Three patients with a deletion in the $14 q 13$ region from the laboratories in Leiden (The Netherlands) and two from Leuven (Belgium) (of which one was previously published ${ }^{12}$ ) were included in the study. In addition, authors from 
papers describing patients with 14q13 deletions and a severe phenotype were contacted in order to obtain DNA. The DNA of one of the sisters described by Iwatani et a $t^{5}$ and patient 1 from the paper by Carré et al ${ }^{11}$ were obtained.

A detailed clinical description of the patients is provided below and summarised in table 1 . We have also included patients from literature with a deletion in 14q13. Patients from literature were included when the size of the deletion was narrowed down using molecular methods, no other chromosomal aberrations were present and basic clinical information was available. Patients from literature with FOXG1 deletions were excluded from this table (see Discussion).

\section{Patient 1}

Patient 1 is a 7-year-old girl, the first child of non-consanguineous parents, born at a gestational age of 42 weeks with a birth weight of $3600 \mathrm{~g}$ (0 SD score, SDS). Pregnancy was uneventful; the delivery was complicated by a decreased fetal heart rate but Apgar scores were normal. The neonatal screening programme showed hypothyroidism for which she was treated accordingly. Since the age of 2 years she displayed a movement disorder described as choreoathetosis and she has a delayed motor development. She showed class I dental malocclusion with absence of 55, 65 and 85, as well as permanent agenesis of 15-17, 25-27, 36-37 and 45-47. There was a discrepancy between her performal IO (76) and verbal IO (105). She attends a regular primary school with a 1-year delay. Physical examination at 7 years of age showed no dysmorphisms apart from deeply-set eyes and widely spaced teeth. Her growth parameters are normal. In the past, NKX2-1 sequencing showed normal results.

\section{Patient 2}

Patient 2 was a 1-week-old male neonate, the first child of nonconsanguineous parents, born after a term pregnancy with normal birth weight. The diagnosis of hypothyroidism was established by the neonatal screening programme. He suffered from recurrent episodes of pulmonary insufficiency and possible pneumonias. His motor development is delayed and restlessness was observed at a young age as well as ataxia, which severely impair his motor skills. Otherwise, his development is normal for his age. Dental examination showed absence of six primary elements and permanent agenesis of 11 elements.

NKX2-1 mutation analysis was included in the suggested investigation but he was lost to follow-up. Physical examination at the ages of 3 and 5 years did not reveal any major dysmorphic features (figure 1). His father reported that the patient experiences sleeping difficulties with short periods of sleeping during the whole night.

\section{Patient 3}

Patient 3 was born as the first child of healthy non-consanguineous parents. In pregnancy, the mother was on paroxetin (20 mg/day). Because of this, a detailed ultrasound scan at 20 weeks of gestation was performed. This detected essentially the same complex cardiac anomaly as postnatal investigations (see below). Amniocentesis showed a normal male karyotype. A 22 q11 deletion was excluded using the fluorescent in situ hybridisation technique.

He was born after 36.3 weeks of gestation, with a birth weight of $2590 \mathrm{~g}$, after an emergency caesarean section because of pre-eclampsia and deterioration of fetal condition. Postnatal cardiac examination showed a complex congenital heart malformation: an interrupted arterial arch type B, bicuspid aortic valve, subvalvular and valvular aortic stenosis, hypoplasia of the annulus of the aorta, and a ventricular septum defect (left ventricular outflow tract obstruction).

Physical examination at the age of 2 weeks showed minor facial dysmorphisms: short palpebral fissures, bilateral earpits, pointed and indented chin, with vertical creases.

At 1 month of age, poor gain of weight necessitated a hybrid Norwood procedure (bilateral banding of the pulmonary arteries and stenting of the ductus arteriosus). After successful recovery, the patient was discharged. His growth and development in this period were unremarkable. At the age of 4 months, his condition was sufficient to undergo a Ross-Konno procedure. The reconstruction was successful; the operation was however complicated by a massive lung bleeding, sadly resulting in perioperative death. Postmortem studies were not performed.

Because of a first degree relative with aortic aneurysm, his father had a cardiac ultrasound with normal results.

NOTCH1 mutation analysis was performed and no mutations were found.

\section{Patient 4}

Patient 4 was a female neonate previously described by Devriendt et al ${ }^{12}$ born after an uncomplicated term pregnancy with a birth weight of $3400 \mathrm{~g}$ (0 SDS). She was admitted with severe respiratory distress and subclinical hypothyroidism was diagnosed. She developed mild choreoathetotic movements and decreased balance control which did not prevent her from winning several sporting competitions. She experienced recurrent pulmonary infections in the past year. Her intelligence is normal but she has trouble processing information and keeping up with a high pace. She attended regular primary school until the 5th year, after which she changed to special education. Physical examination at the age of $10-15$ years showed normal growth parameters (weight $51.2 \mathrm{~kg}$ (0.9 SDS), height $159.9 \mathrm{~cm}$ (0.6 SDS) and head circumference $54.8 \mathrm{~cm}(0.6 \mathrm{SDS})$ ) and several missing dental elements.

\section{Patient 5}

Patient 5 was a woman in her thirties, the first child of nonconsanguineous parents born after an uncomplicated term pregnancy with a birth weight of $3600 \mathrm{~g}$ (+0.5 SDS). A perforated lung was diagnosed neonatally. Hypothyroidism was diagnosed in childhood. She suffers from recurrent respiratory infections/chronic bronchitis. Her developmental milestones were delayed (walking at 2 years of age) and she has mild intellectual disability. She attended special education. She has short stature $(159 \mathrm{~cm},-2 \mathrm{SDS})$ and has a normal head circumference of $53.9 \mathrm{~cm}$. She has a movement disorder and falls frequently. There is an absence of elements 55, 65, 75 and 85 as well as permanent agenesis of $5-8$ in all quadrants.

\section{Patient 6}

Patient 6 is the eldest of the two sisters described by Iwatani et al. ${ }^{5}$ She was born to non-consanguineous parents at a gestational age of 41 weeks with a birth weight of $3150 \mathrm{~g}$ (+0.1 SDS). She was admitted recurrently with respiratory difficulties, failure to thrive, severe feeding difficulties and microcephaly. Her development was severely delayed with absence of head control. She died of respiratory failure at the age of 13 years. Her younger sister had a similar clinical picture and died of respiratory failure at the age of 3 years.

\section{Patient 7}

Patient 7 was previously published as patient 1 in the paper by Carre et al. ${ }^{11}$ She was born at term and presented with mild 


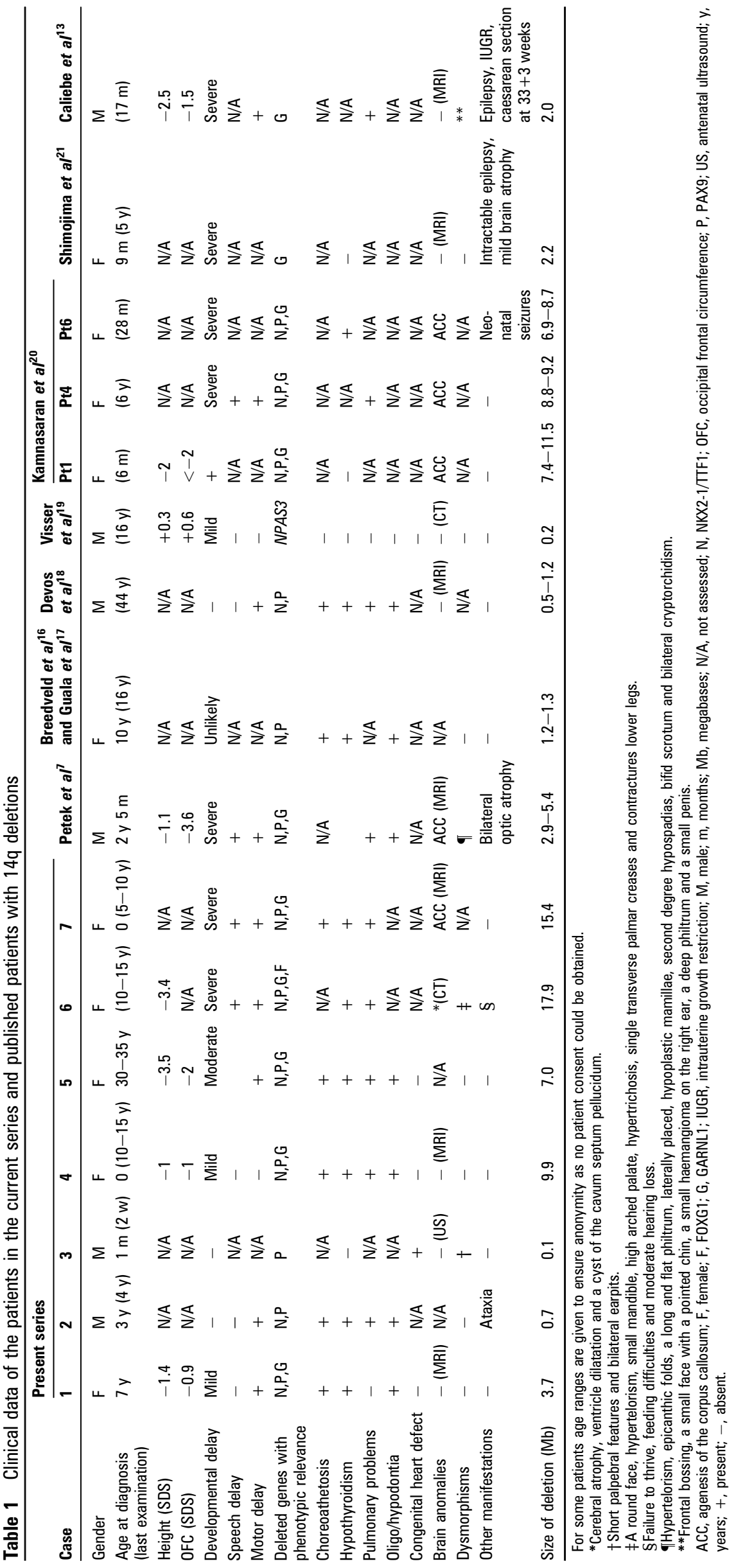




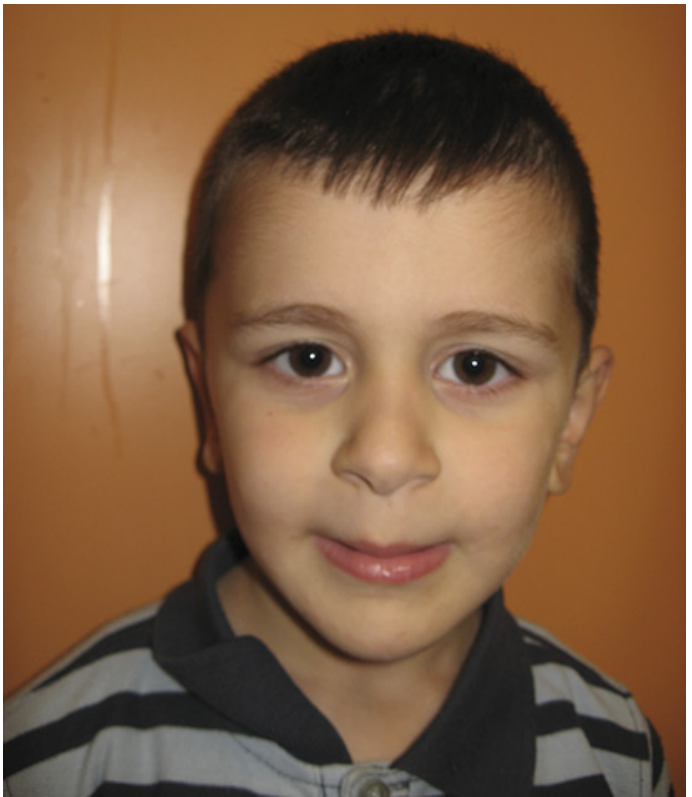

Figure 1 Face of patient 2, aged 3 years and 5 months, showing no apparent dysmorphisms. Note that the apparent smooth philtrum is secondary to his tendency to grimace during posing.

hypothyroidism and infant respiratory distress syndrome for which she needed ventilation for 8 days. She was dependent on oxygen for the first 3 months of life. At 7 months of age, her head circumference was $38.1 \mathrm{~cm}(-3.5 \mathrm{SDS})$. Atactic movements and psychomotor delay were observed during the first year of life. At the age of around 5 years she was severely intellectually disabled.

\section{RESULTS OF MOLECULAR KARYOTYPING}

Array analysis in these seven patients showed 14q13 deletions varying in size from $105 \mathrm{~kb}$ to $16.96 \mathrm{Mb}$ (table 2, figure 2). Three deletions were proven to be de novo, a fourth was most likely de novo, two were not tested and one was due to a familial insertional translocation.

\section{DISCUSSION \\ Impact of FOXG1 on the 14q13 deletion phenotype}

In this series, seven patients with a deletion in chromosome region $14 \mathrm{q} 13$ are described (table 1 , figure 2 ). There appear to be two groups of patients: those who suffer from severe intellectual disability and multiple congenital anomalies, and those whose phenotype is milder and largely determined by haploinsufficiency of NKX2-1 and PAX9.

Two of our patients were severely intellectually disabled (patients 6 and 7). Obtaining the DNA and extending the previously performed investigations allowed us to explain the severe intellectual disability in patient 6 and her sister ${ }^{5}$ by the deletion of FOXG1. Haploinsufficiency of FOXG1 causes a congenital variant of Rett syndrome, with poor reactivity, hypotonia and severe microcephaly. ${ }^{23} 24$ Patient 7 also showed severe intellectual disability, yet retained FOXG1. The most likely explanation for the difference between this patient and those with mild intellectual disability is the size of the deletion $(15.5 \mathrm{Mb})$. Especially the distal part of this deletion is quite rich in genes. Additionally, Kortüm et a ${ }^{25}$ have convincingly argued that there are long range cis-regulatory elements of FOXG1 in the $1 \mathrm{Mb}$ downstream of FOXG1. Although this deletion is just outside the suggested region, a positional effect on FOXG1 cannot be excluded.

We have searched the literature for patients with deletions including chromosome region $14 q 13$. We included papers in which the size of the deletion was narrowed down using molecular methods and basic clinical information was available. Since haploinsufficiency of FOXG1 results in a well-described phenotype, we decided to exclude patients with a clear deletion of FOXG1 from table 1. Indeed, it is our opinion that inclusion of these patients in genotype-phenotype correlation studies confounds the 'true' phenotype of patients with a $14 \mathrm{q} 13$ deletion. A recent paper ${ }^{14}$ which claims to describe the phenotype of patients with a $14 \mathrm{q}$ deletion is therefore not representative for patients whose 14q13 deletion does not include FOXG1.

Most of the reported patients with a deletion in the $14 \mathrm{q}$ region have a severe phenotype. In some cases, this is sufficiently explained by haploinsufficiency of FOXG1 as in the recent publication by Torgyekes et $a l,{ }^{14}$ and patient 5 in the paper by

Table 2 Size, location and number of genes in the chromosome 14 deletions of each patient

\begin{tabular}{|c|c|c|c|c|c|c|c|}
\hline $\begin{array}{l}\text { Case ID } \\
\text { (DECIPHER code) }\end{array}$ & Platform & Start position* & End position* & Size & No of genes* & Additional findings (if any) & $\begin{array}{l}\text { Status of inheritance } \\
\text { (origin if known) }\end{array}$ \\
\hline $1(264287)$ & Affymetrix $262 \mathrm{~K} \mathrm{Nspl}$ & 35.199 .722 & 38.886 .152 & $3.69 \mathrm{Mb}$ & 20 & & Most likely de novo (p)† \\
\hline $2(250393)$ & Affymetrix 262K Nspl & 36.010 .235 & 36.727 .597 & $717 \mathrm{~kb}$ & 5 & & de novo (m) \\
\hline $3(264289)$ & Affymetrix 262K Nspl & 36.114 .849 & 36.219 .911 & $105 \mathrm{~kb}$ & 4 & $\begin{array}{l}\text { Maternally inherited } \\
\text { deletion on } 11 q\end{array}$ & de novo (p) \\
\hline 4 & OGT 180k & 34.077 .461 & 43.971 .142 & $9.89 \mathrm{Mb}$ & 34 & $\begin{array}{l}\text { An additional duplication on } \\
\text { chromosome 1q of } 264 \mathrm{~kb} \\
\text { was found containing the IPP } \\
\text { and MAST2 genes }\end{array}$ & De novo \\
\hline 5 & OGT 180k & 33.670 .261 & 40.648 .438 & $6.98 \mathrm{Mb}$ & 34 & & Not tested \\
\hline $6(264290)$ & Affymetrix $262 \mathrm{~K} \mathrm{Nspl}$ & 24.383 .933 & 41.340 .975 & $16.96 \mathrm{Mb}$ & 54 & $\begin{array}{l}\text { An additional duplication on } \\
\text { chromosome } 10 \mathrm{q} \text { of } 454 \mathrm{~kb} \\
\text { containing NRG3 was also } \\
\text { found. On chromosome } 8 \mathrm{q} \\
\text { a } 2.27 \mathrm{Mb} \text { duplication was } \\
\text { found which has been described } \\
\text { as a genomic variant in the } \\
\text { Japanese population }{ }^{22}\end{array}$ & $\begin{array}{l}\text { Familial insertional } \\
\text { translocation } \neq\end{array}$ \\
\hline 7 (264291) & Affymetrix $262 \mathrm{~K} \mathrm{Nspl}$ & 29.701 .682 & 45.144 .380 & $15.44 \mathrm{Mb}$ & 59 & & Not tested \\
\hline
\end{tabular}




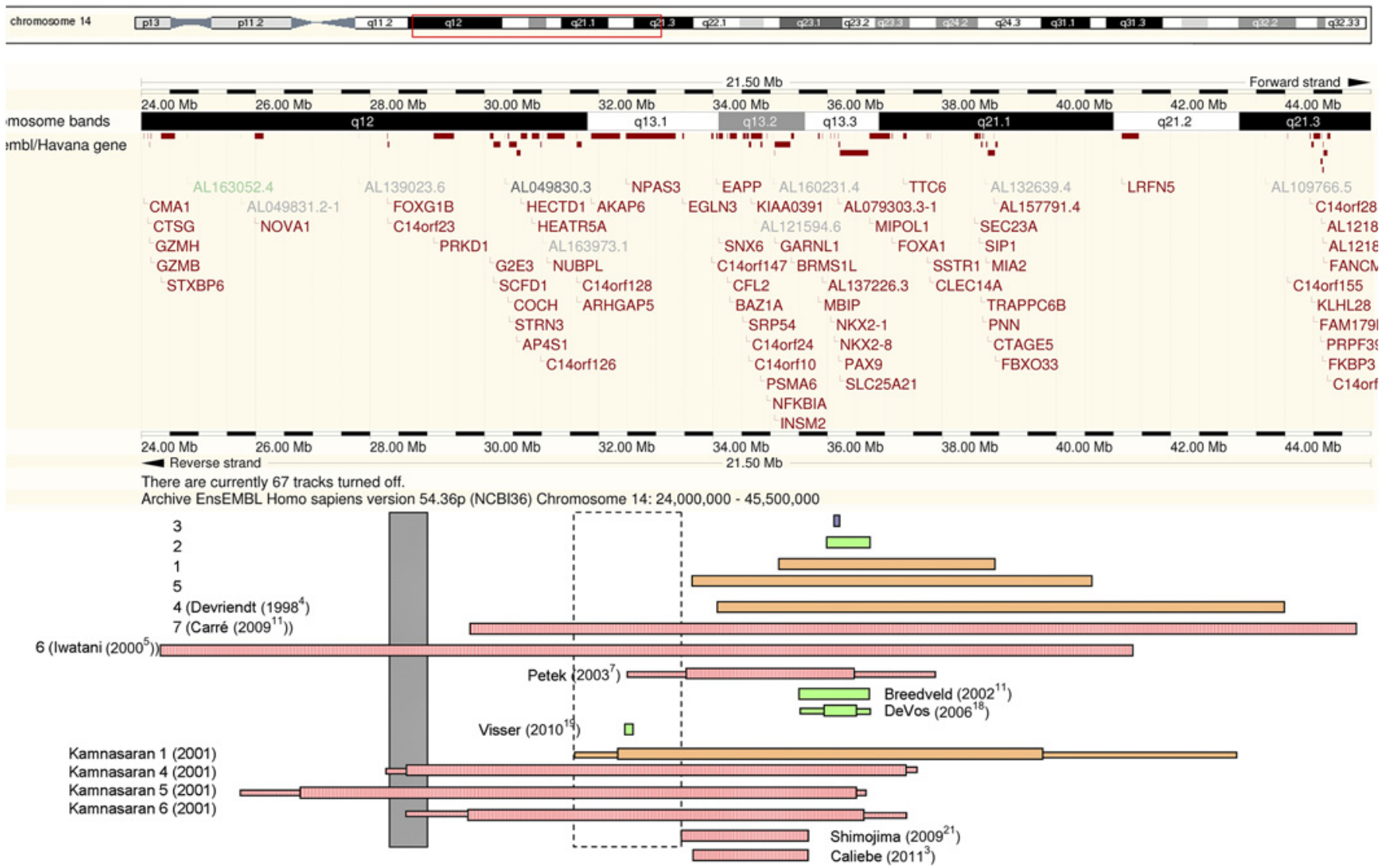

Figure 2 Graphical representation of the region spanned by the deletions of each of the patients. The first seven patients are those described in this paper. Below, the patients from relevant papers from literature are depicted. Thick bars represent the minimal size of the deletion, and thinner bars represent the maximal size of the deletion. The colour represents the severity of the phenotype: mild (green), moderate (orange) or severe (red). Since patient 3 died at a young age, disease severity could not be assessed. The dark box represents the putative regulatory region for FOXG1, and the white box represents the remaining candidate region for agenesis of the corpus callosum (see Discussion). The size and location from the deletions in literature depicted here are determined using the marker data reported in literature. Please note that there is a discrepancy between the microscopic karyotype of patient 1 of Kamnasaran et al $(2001)^{20}(46, X X, d e l(14)(q 11.2 q 21.1))$ and the results of marker analysis for this patient as presented in Kamnasaran et al (2005). ${ }^{9}$

Kamnasaran et al. ${ }^{20}$ The severity of the phenotype of patients 4 and 6 described in the latter paper might well be explained by the positional effect of these deletions on FOXG1 as these deletions span the region with putative cis-regulatory elements ${ }^{25}$ (figure 2).

Only three patients in the literature with a severe phenotype cannot be explained by FOXG1-related deletions. The first of these patients was reported by Petek et al. ${ }^{7}$ Unfortunately, it was not possible to obtain DNA from this patient to determine the size of the deletion. This patient has a phenotype with severe intellectual disability and bilateral optic atrophy. Most of the deletion of this patient overlaps with deletions from our patients who have a much milder phenotype. The only gene outside the common deleted region is NPAS3, which might be a gene relevant for developmental delay, but is unlikely to be the single cause of the severe phenotype of this patient since the patient presented by Visser et al ${ }^{19}$ with a deletion of the first exon of NPAS3 has an IO of 76. It is likely that this deletion will preclude translation and therefore lead to haploinsufficiency of NPAS3. A mutation in another gene or a copy number variant elsewhere might be the cause of the phenotype in the patient reported by Petek et al. ${ }^{7}$ The presence of a recessive mutation in the second copy of one of the deleted genes cannot be excluded.

The other two patients with a severe phenotype and no FOXG1 involvement share a highly similar deletion and phenotype. The first was published by Shimojima et $a l^{21}$ and was reported to be severely intellectually disabled and had intractable epilepsy. The second patient was reported by Caliebe et $a l^{13}$ and was diagnosed with severe developmental delay and epilepsy. At the age of 3 years, he was diagnosed with pneumonia. In the further course he developed symptoms of haemophagocytic lymphohistiocytosis. He died due to organ failure. This patient showed severe intrauterine growth retardation and was delivered by caesarean section at $33+3$ weeks of gestation. A small placenta was found and he needed 10 days of ventilation after birth. An influence of the aforementioned on his phenotype cannot be excluded. The deletions of these patients include GARNL1. It has been suggested ${ }^{2126}$ that haploinsufficiency of GARNL1/TULIP1 might be the cause of developmental delay and epilepsy. Indeed, heterozygous mutations were found in 4/140 of such patients, although these mutations were all inherited from healthy parents. Since three of our patients with mild to moderate developmental delay and no epilepsy had a deletion of this gene, we consider it unlikely that mutations in GARNL1 are an important cause of severe intellectual disability. However, it is striking that these two patients share almost the same deletion and have comparable phenotypes. Then again, the deletion of our patient 5 completely overlaps (and is $5 \mathrm{Mb}$ larger) and she had moderate intellectual disability and no epilepsy. Imprinting effects can be ruled out as 
a possible cause, since the patient reported by Petek et al ${ }^{7}$ had a deletion on the maternal allele and the patient reported by Shimojima et $a^{21}$ had a deletion on the paternal allele. Alternatively, the combination of the deletion and a (relatively) frequently occurring SNP in this region might cause a severe phenotype.

\section{Impact of NKX2-1 and PAX9 on the 14q13 deletion phenotype}

In contrast to these patients with a severe phenotype, our patient 2 had no developmental delay, patients 1 and 4 had mild developmental delay and patient 5 had moderate developmental delay. These patients have partially overlapping deletions ranging from $717 \mathrm{~kb}$ to $10 \mathrm{Mb}$. It appears that haploinsufficiency of the genes in these deletions does not lead to severe intellectual disability.

All of these patients had a deletion of NKX2-1 and PAX9, which result in a clear phenotype. Haploinsufficiency of $N K X 2-1$ causes brain-lung-thyroid syndrome, consisting of a triad of extremely variable manifestations. The brain manifestations consist of choreoathetosis which is present in most patients to a variable degree (7/8 in table 1$)$. The lung manifestations range from severe pulmonary insufficiency (7/8 in table 1$)$, sometimes leading to death, to no pulmonary complaints at all (as in our patient 1). The thyroid manifestations ( $8 / 8$ in table 1 ) are often detected in congenital screening but sometimes subclinical hypothyroidism is observed. It has previously been stated that chromosome 14q13 deletions show exactly the same phenotype as NKX2-1 mutations, ${ }^{6}$ but this is not completely accurate. With an increasing size of the deletion the probability of intellectual disability, ranging from mild to severe, increases. In contrast to what has been suggested, ${ }^{16}$ deletions of NKX2-1 do not result in a more severe brain-lung-thyroid-phenotype than mutations in NKX2-1. ${ }^{11}$

Not all patients with PAX9 haploinsufficiency had oligodontia; however, in none of these the absence of oligodontia was explicitly reported. In our series, oligodontia was observed in all patients where the appropriate investigations were performed (4/4), indicating that penetrance of this phenotype is probably high, and that it might have been missed in some of the reported patients. In some cases, it is perhaps because they were too young for oligodontia or permanent agenesis to manifest without performing an orthopantomogram.

Patient 3 appears to be an outlier in our group of patients with regard to his phenotypic manifestations. He had a severe cardiac phenotype but the smallest deletion, including only four genes (three Refseq genes). Since none of the other patients are described with a cardiac phenotype we consider it unlikely that this deletion is the cause of his cardiac problems. Since one of these genes, NKX2-8, is highly expressed in early heart progenitor cells, ${ }^{27} 28$ we decided to sequence this gene in patient 3 but did not find any mutations on the other allele. Other causes of his cardiac phenotype such as a 22q11 deletion, a NOTCH1 mutation or other copy number variations were excluded.

\section{Reviewing the evidence for an HPE locus}

Kamnasaran et al ${ }^{9}$ have defined an HPE locus (HPE8) mainly using patients described in an earlier paper, ${ }^{20}$ but none of these patients were actually diagnosed with HPE. Instead, all were diagnosed with agenesis of the corpus callosum (ACC). Although there is a relation between ACC and HPE, and ACC might be a minimal form of HPE, not all cases of ACC should be classified as HPE. ${ }^{29}$ It is therefore more likely that the HPE8 locus is actually an ACC locus rather than an HPE locus. One of the patients in our study was diagnosed with ACC but most had normal MRI findings. Considering only those patients where ACC was formally excluded by MRI, a relatively small region of interest remains (as indicated in figure 2). This region contains four genes: C140rf128, ARHGAP5, AKAP6 and NPAS3. NPAS3 is partially deleted in patient 58 described by Visser et al, ${ }^{19}$ who did not have HPE or ACC (as determined by CT scan) (Dr S Kant, personal communication) and in our patient 6 , who has a severe phenotype but no HPE. However, since ACC may be missed on a CT scan NPAS3 remains a candidate gene.

\section{CONCLUSION}

Although we cannot exclude that HPE 8 is associated with HPE, the poor a priori evidence for this locus, combined with the results from our studies, provides little support for an HPE locus on chromosome 14q13. However, there might be a locus for ACC containing four genes.

The phenotype of patients with a $14 q 13$ deletion is largely determined by the involvement of FOXG1, NKX2-1 and PAX9. From our series and published patients it is clear that deletions involving FOXG1, including an $1 \mathrm{Mb}$ upstream region, cause a severe phenotype. In our series, deletions involving NKX2-1 and $P A X 9$ with a size of up to $10 \mathrm{Mb}$ result in a clinically recognisable phenotype with mostly mild intellectual disability, implicating that these deletions are relatively well tolerated. However, there are three published patients with a relatively small overlapping deletion with severe phenotypes. No explanation was found for this discrepancy. To improve genotypephenotype relationships in the future, it is important that clinical descriptions of all patients with copy number variations are made publicly available in databases such as DECIPHER (http://decipher.sanger.ac.uk).

Acknowledgements We would like to acknowledge Dr E Petek for his efforts to try and locate his patient with a 14q13 deletion, Dr S Kant for kindly providing information on one of the published patients and Ing. CAJ Bosch for technical assistance.

Contributors GS and EB conceived the study and wrote the paper. YS sequenced the NKX2-8 gene. AG and CR performed SNP-array data analysis. GS, AC, MH, AH, SALO, $A T, H M, M P, K D$ and EB phenotyped the patients. All authors read, revised and approved the final version of the manuscript.

\section{Competing interests None.}

\section{Patient consent Obtained.}

Ethics approval Most investigations were performed in the course of routine clinical care. In the remaining cases the molecular karyotyping was performed to delineate the exact size and location of a deletion already found by other methods. No new patient samples were required.

Provenance and peer review Not commissioned; externally peer reviewed.

Data sharing statement All CNV information is present in the paper. No additional data will be uploaded to repositories.

\section{REFERENCES}

1. Bonaglia MC, Marelli S, Novara F, Commodaro S, Borgatti R, Minardo G, Memo L, Mangold E, Beri S, Zucca C, Brambilla D, Molteni M, Giorda R, Weber RG, Zuffardi O. Genotype-phenotype relationship in three cases with overlapping 19p13.12 microdeletions. Eur J Hum Genet 2010;18:1302-9.

2. Feenstra I, Vissers LE, Orsel M, van Kessel AG, Brunner HG, Veltman JA, van Ravenswaaij-Arts CM. Genotype-phenotype mapping of chromosome 18q deletions by high-resolution array $\mathrm{CGH}$ : an update of the phenotypic map. Am J Med Genet $A$ 2007;143A:1858-67.

3. Chen CP, Lee CC, Chen LF, Chuang CY, Jan SW, Chen BF. Prenatal diagnosis of de novo proximal interstitial deletion of $14 q$ associated with cebocephaly. J Med Genet 1997:34:777-8.

4. Devriendt K, Fryns JP, Chen CP. Holoprosencephaly in deletions of proximal chromosome 14q. J Med Genet 1998;35:612. 
5. Iwatani N, Mabe H, Devriendt K, Kodama M, Miike T. Deletion of NKX2.1 gene encoding thyroid transcription factor-1 in two siblings with hypothyroidism and respiratory failure. J Pediatr 2000;137:272-6.

6. Krude H, Schutz B, Biebermann H, von Moers A, Schnabel D, Neitzel H, Tonnies H, Weise D, Lafferty A, Schwarz S, DeFelice M, von Deimling A, van Landeghem F, DiLauro R, Gruters A. Choreoathetosis, hypothyroidism, and pulmonary alterations due to human NKX2-1 haploinsufficiency. J Clin Invest 2002;109:475-80.

7. Petek E, Plecko-Startinig B, Windpassinger C, Egger H, Wagner K, Kroisel PM. Molecular characterisation of a $3.5 \mathrm{Mb}$ interstitial $14 \mathrm{q}$ deletion in a child with several phenotypic anomalies. J Med Genet 2003;40:e47.

8. Su PH, Chen SJ, Lee IC, Wang KL, Chen JY, Hung HM, Lee CF. Interstitial deletion of chromosome 14q in a Taiwanese infant with microcephaly. J Formos Med Assoc 2004:103:385-7.

9. Kamnasaran D, Chen CP, Devriendt K, Mehta L, Cox DW. Defining a holoprosencephaly locus on human chromosome $14 q 13$ and characterization of potential candidate genes. Genomics 2005;85:608-21.

10. Segawa Y, Itokazu N, Hirose A, Nakagawa S, Takashima S. A case of partial 14qwith facial features of holoprosencephaly and hydranencephaly. Pediatr Neurol 2007;37:51-4.

11. Carre A, Szinnai G, Castanet M, Sura-Trueba S, Tron E, Broutin-L'Hermite I, Barat P, Goizet C, Lacombe D, Moutard ML, Raybaud C, Raynaud-Ravni C, Romana S, Ythier H, Leger J, Polak M. Five new TTF1/NKX2.1 mutations in brain-lung-thyroid syndrome: rescue by PAX8 synergism in one case. Hum Mol Genet 2009;18:2266-76.

12. Devriendt K, Vanhole C, Matthijs G, de Zegher F. Deletion of thyroid transcription factor-1 gene in an infant with neonatal thyroid dysfunction and respiratory failure. $N$ Engl J Med 1998;338:1317-18

13. Caliebe A, Martin Subero JI, Muhle H, Gesk S, Janig U, Krause M, Plendl H, Stephani U, Siebert R, Eckmann-Scholz C. A 2 Mb deletion in 14q13 associated with severe developmental delay and hemophagocytic lymphohistiocytosis. Eur J Med Genet 2011;54:e505-9.

14. Torgyekes E, Shanske AL, Anyane-Yeboa K, Nahum O, Pirzadeh S, Blumfield E, Jobanputra $\mathrm{V}$, Warburton D, Levy B. The proximal chromosome 14q microdeletion syndrome: delineation of the phenotype using high resolution SNP oligonucleotide microarray analysis (SOMA) and review of the literature. Am J Med Genet $A$ 2011;155A:1884-96.

15. Gijsbers AC, Lew JY, Bosch CA, Schuurs-Hoeijmakers JH, van Haeringen A, den Hollander NS, Kant SG, Bijlsma EK, Breuning MH, Bakker E, Ruivenkamp CA. A new diagnostic workflow for patients with mental retardation and/or multiple congenital abnormalities: test arrays first. Eur J Hum Genet 2009:17:1394-402.

16. Breedveld GJ, van Dongen JW, Danesino C, Guala A, Percy AK, Dure LS, Harper P, Lazarou LP, van der Linde H, Joosse M, Gruters A, MacDonald ME, de Vries BB, Arts WF, Oostra BA, Krude H, Heutink P. Mutations in TITF-1 are associated with benign hereditary chorea. Hum Mol Genet 2002;11:971-9.

17. Guala A, Falco V, Breedveld G, De Filippi P, Danesino C. Deletion of PAX9 and oligodontia: a third family and review of the literature. Int J Paediatr Dent 2008:18:441-5.
18. Devos D, Vuillaume I, de Becdelievre A, de Martinville B, Dhaenens CM, Cuvellier JC, Cuisset JM, Vallee L, Lemaitre MP, Bourteel H, Hachulla E, Wallaert B, Destee A, Defebvre L, Sablonniere B. New syndromic form of benign hereditary chorea is associated with a deletion of TITF-1 and PAX-9 contiguous genes. Mov Disord 2006; 21:2237-40.

19. Visser R, Gijsbers A, Ruivenkamp C, Karperien M, Reeser HM, Breuning MH, Kant SG, Wit JM. Genome-wide SNP array analysis in patients with features of sotos syndrome. Horm Res Paediatr 2010;73:265-74.

20. Kamnasaran D, O'Brien PC, Schuffenhauer S, Quarrell O, Lupski JR, Grammatico P, Ferguson-Smith MA, Cox DW. Defining the breakpoints of proximal chromosome $14 q$ rearrangements in nine patients using flow-sorted chromosomes. Am J Med Genet 2001:102:173-82.

21. Shimojima K, Komoike Y, Tohyama J, Takahashi S, Paez MT, Nakagawa E, Goto Y Ohno K, Ohtsu M, Oguni H, Osawa M, Higashinakagawa T, Yamamoto T. TULIP1 (RALGAPA1) haploinsufficiency with brain development delay. Genomics 2009;94:414-22.

22. Harada N, Takano J, Kondoh T, Ohashi H, Hasegawa T, Sugawara H, Ida T, Yoshiura K, Ohta T, Kishino T, Kajii T, Niikawa N, Matsumoto N. Duplication of 8p23.2: a benign cytogenetic variantN/A. Am J Med Genet 2002;111:285-8.

23. Mencarelli MA, Kleefstra T, Katzaki E, Papa FT, Cohen M, Pfundt R, Ariani F, Melon I, Mari F, Renieri A. 14q12 microdeletion syndrome and congenital variant of Rett syndrome. Eur J Med Genet 2009;52:148-52.

24. Jacob FD, Ramaswamy V, Andersen J, Bolduc FV. Atypical Rett syndrome with selective FOXG1 deletion detected by comparative genomic hybridization: case report and review of literature. Eur J Hum Genet 2009;17:1577-81.

25. Kortum F, Das S, Flindt M, Morris-Rosendahl DJ, Stefanova I, Goldstein A, Horn D, Klopocki E, Kluger G, Martin P, Rauch A, Roumer A, Saitta S, Walsh LE, Wieczorek D, Uyanik G, Kutsche K, Dobyns WB. The core FOXG1 syndrome phenotype consists of postnatal microcephaly, severe mental retardation, absent language, dyskinesia, and corpus callosum hypogenesis. J Med Genet 2011;48:396-406.

26. Schwarzbraun T, Vincent JB, Schumacher A, Geschwind DH, Oliveira J, Windpassinger C, Ofner L, Ledinegg MK, Kroisel PM, Wagner K, Petek E. Cloning, genomic structure, and expression profiles of TULIP1 (GARNL1), a brain-expressed candidate gene for 14q13-linked neurological phenotypes, and its murine homologue. Genomics 2004;84:577-86.

27. Brand T, Andree B, Schneider A, Buchberger A, Arnold HH. Chicken NKx2-8, a novel homeobox gene expressed during early heart and foregut development. Mech Dev 1997;64:53-9.

28. Reecy JM, Yamada M, Cummings K, Sosic D, Chen CY, Eichele G, Olson EN, Schwartz RJ. Chicken Nkx-2.8: a novel homeobox gene expressed in early heart progenitor cells and pharyngeal pouch-2 and -3 endoderm. Dev Biol 1997; 188:295-311.

29. Schell-Apacik CC, Wagner K, Bihler M, Ertl-Wagner B, Heinrich U, Klopocki E, Kalscheuer VM, Muenke M, von Voss $\mathrm{H}$. Agenesis and dysgenesis of the corpus callosum: clinical, genetic and neuroimaging findings in a series of 41 patients. Am J Med Genet A 2008;146A:2501-11. 


\section{Further delineation of the phenotype of chromosome 14q13 deletions: (positional) involvement of FOXG1 appears the main determinant of phenotype severity, with no evidence for a holoprosencephaly locus}

Gijs W E Santen, Yu Sun, Antoinet C J Gijsbers, et al.

J Med Genet published online May 25, 2012

doi: 10.1136/jmedgenet-2011-100721

Updated information and services can be found at:

http://jmg.bmj.com/content/early/2012/05/24/jmedgenet-2011-100721.full.html

These include:

References This article cites 29 articles, 6 of which can be accessed free at: http://jmg.bmj.com/content/early/2012/05/24/jmedgenet-2011-100721.full.html\#ref-list-1

$\mathbf{P}<\mathbf{P} \quad$ Published online May 25, 2012 in advance of the print journal.

Email alerting Receive free email alerts when new articles cite this article. Sign up in service the box at the top right corner of the online article.

Notes

Advance online articles have been peer reviewed, accepted for publication, edited and typeset, but have not not yet appeared in the paper journal. Advance online articles are citable and establish publication priority; they are indexed by PubMed from initial publication. Citations to Advance online articles must include the digital object identifier (DOIs) and date of initial publication.

To request permissions go to:

http://group.bmj.com/group/rights-licensing/permissions

To order reprints go to:

http://journals.bmj.com/cgi/reprintform

To subscribe to BMJ go to:

http://group.bmj.com/subscribe/ 